\title{
Influence of the number of water molecules on the mechanism of $\mathbf{N}$-sulfinylaniline hydrolysis ${ }^{1}$
}

\author{
Elena V. Ivanova and Heidi M. Muchall
}

\begin{abstract}
The mechanism of the uncatalyzed hydrolysis of $N$-sulfinylaniline $(\mathrm{Ph}-\mathrm{N}=\mathrm{S}=\mathrm{O})$ has been studied with B3LYP/6-31+G(2d,2p) in the gas phase, with explicit treatment of water molecules. Hydrolysis involves water attack on sulfur, with a close to perpendicular alignment of a water molecule and the NSO plane in both prereaction complexes and transition states for the rate-determining step. Consequently, the distance of the weak S $\cdots \mathrm{O}$ interaction, together with the efficiency of protonation of either nitrogen (attack across the $\mathrm{N}=\mathrm{S}$ bond) or oxygen (attack across the $\mathrm{S}=\mathrm{O}$ bond) atoms of the NSO group, determines the height of the activation barrier for hydrolysis. While the reaction with one water molecule is characterized by an unreasonably high enthalpy of activation, a cooperative effect from the weak interactions appears with the inclusion of a second water molecule, where both participate in the reaction, and the activation enthalpy drops significantly. The preference for attack across the $\mathrm{S}=\mathrm{O}$ bond that is found in the reaction with one water molecule switches to a dominance of attack across the $\mathrm{N}=\mathrm{S}$ bond in the reaction with three water molecules.
\end{abstract}

Key words: $N$-sulfinylaniline, hydrolysis, mechanism, density functional theory (DFT).

Résumé : Faisant appel à des calculs théoriques au niveau B3LYP/6-31+G(2d,2p), on a étudié le mécanisme de l'hydrolyse non catalysée du $N$-sulfinylaniline $(\mathrm{Ph}-\mathrm{N}=\mathrm{S}=\mathrm{O})$ en phase gazeuse, en faisant un traitement explicite des molécules d'eau. Dans l'étape cinétiquement déterminante, l'hydrolyse implique une attaque de l'eau sur le soufre, avec un alignement pratiquement perpendiculaire d'une molécule d'eau et du plan NSO tant dans les complexes préréactionnels que dans les états de transition. En conséquence, la distance de la faible interaction S ...O ainsi que l'efficacité de la protonation de l'atome d'azote (attaque à travers la liaison $\mathrm{N}=\mathrm{S}$ ) ou de l'atome d'oxygène (attaque à travers la liaison $\mathrm{S}=\mathrm{O}$ ) du groupe NSO détermine la hauteur de la barrière d'activation de l'hydrolyse. Alors que la réaction avec une molécule d'eau est caractérisée par une enthalpie d'activation anormalement élevée, il semble se développer un effet de synergie avec les interactions faibles lors de l'inclusion d'une deuxième molécule d'eau alors que les deux participent à la réaction et que l'enthalpie d'activation diminue d'une façon significative. La préférence pour l'attaque à travers la liaison $\mathrm{S}=\mathrm{O}$ qui caractérise la réaction avec une molécule d'eau se déplace vers une dominance pour une attaque à travers la liaison $\mathrm{N}=\mathrm{S}$ dans la réaction avec trois molécules d'eau.

Mots clés : $N$-sulfinylaniline, hydrolyse, mécanisme, théorie de la densité fonctionnelle.

[Traduit par la Rédaction]

\section{Introduction}

Our interest in the electronic and molecular structures of NSO species $(1,2)$ is closely related to their reactivity. $\mathrm{N}$ Sulfinylamines $(\mathrm{R}-\mathrm{N}=\mathrm{S}=\mathrm{O})$ were first prepared by Michaelis in 1890 (3) and their reaction with water was one of the first properties to be observed experimentally. While aromatic $N$ sulfinylamines are insoluble in water and hydrolized very slowly in it as well as in dilute acids, warm alkaline solutions or concentrated acids lead to their rapid hydrolysis (4). Aromatic $N$-sulfinylamines in particular are widely employed in synthetic organic chemistry, as they readily un-

Received 29 April 2005. Published on the NRC Research Press Web site at http://canjchem.nrc.ca on 29 November 2005.

E.V. Ivanova and H.M. Muchall. ${ }^{2}$ Centre for Research in Molecular Modeling and Department of Chemistry and Biochemistry, Montreal, QC H4B 1R6, Canada.

${ }^{1}$ This article is part of a Special Issue dedicated to organic reaction mechanisms.

${ }^{2}$ Corresponding author (e-mail: muchall@alcor.concordia.ca).

\section{Scheme 1.}

$$
\mathrm{RNSO}+\mathrm{H}_{2} \mathrm{O} \longrightarrow \mathrm{RNHS}(\mathrm{O}) \mathrm{OH} \longrightarrow \mathrm{RNH}_{2}+\mathrm{SO}_{2}
$$

dergo a variety of cycloaddition reactions to yield N,Sheterocycles (Diels-Alder reactions as both dienes and dienophiles (5-7), 1,2-cycloadditions, and 1,3-dipolar additions $(8,9))$. Common to all these reactions is the attack on the sulfur of the NSO group, and hydrolysis can be considered as the prototype reaction. Therefore, an understanding of the initial steps of the hydrolysis reaction mechanism of $\mathrm{N}$-sulfinylaniline is fundamental to its exploitation in similar reactions involving $N$-sulfinylamines.

The mechanism for hydrolysis of $\mathrm{N}$-sulfinylamines is believed to proceed through nucleophilic addition of a water molecule to the NSO group with the formation of sulfinamic acid, followed by the acid's fast decomposition to sulfur dioxide and a primary amine (Scheme 1) (10). Aromatic $N$ sulfinylamines are known to be somewhat resistant towards water, whereas aliphatic $N$-sulfinylamines hydrolyze more readily (4). For $N$-sulfinylaniline ( $\mathrm{Ph}-\mathrm{N}=\mathrm{S}=\mathrm{O}$ ), kinetics studies using UV spectroscopy showed neutral hydrolysis to be a 
slow process $(11,12)$, with an induction period of approximately $4 \mathrm{~h}$ (12). The reaction is complicated by autocatalysis from aniline, formed as a product of the reaction, which explains the relatively low activation energy of $9.88 \mathrm{kcal} \mathrm{mol}^{-1}$ $(1 \mathrm{cal}=4.184 \mathrm{~J})$ in a water-1,4-dioxane $(1: 1)$ solution $(11)$. In the presence of pyridine as a base or with a combination of pyridine and a carboxylic acid, the rate of reaction increases significantly (12). General base catalysis was proposed for the hydrolysis in the presence of pyridine, where the formation of a pyridine-water complex increases the nucleophilic properties of water and facilitates its interaction with the electrophilic sulfur atom. This is proposed to be the rate-determining step of hydrolysis. It is a third-order reaction, first-order in each $N$-sulfinylaniline, water, and pyridine, with an overall rate constant of $2.96 \times 10^{3} \mathrm{~L}^{2} \mathrm{~mol}^{-2} \mathrm{~s}^{-1}$ and a low enthalpy of activation of $5.7 \mathrm{kcal} \mathrm{mol}^{-1}$ for the 20-40 ${ }^{\circ} \mathrm{C}$ temperature range.

For the combined catalysis by pyridine and a carboxylic acid, initial protonation of either nitrogen or oxygen atoms of the NSO group was predicted (12). This would lead to an increase in the net positive charge on the sulfur atom and promote the addition of a water molecule to the NSO group. This acid catalysis is not part of the discussion in the present paper.

While literature data on the hydrolysis of $N$-sulfinyl compounds are limited $(11,12)$, the hydrolysis of their cumulated analogs (isocyanates, $\mathrm{R}-\mathrm{N}=\mathrm{C}=\mathrm{O}$ ) was intensively studied, both experimentally (13-15) and computationally (16). Based on their structural similarities, one might expect similar reactivities for these two classes of compounds. And while the NCO group is more or less linear, whereas the NSO group is bent with a sulfur bond angle of $120.6^{\circ}$ as determined from X-ray diffraction analysis (17), the similar solvent kinetic isotope effects $k\left(\mathrm{H}_{2} \mathrm{O}\right) / k\left(\mathrm{D}_{2} \mathrm{O}\right)$ of 1.65 for PhNCO (14) and 1.73 for PhNSO (12) seem to support the idea of similar reactivities and possibly similar mechanisms in the hydrolysis of these compounds.

A second-order dependence on water was found in the neutral hydrolysis of alkyl- and aryl-substituted isocyanates $(13,14,16)$, where one molecule acts as a general acid and the other as a general base. This is closely related to the base-catalyzed hydrolysis of $\mathrm{N}$-sulfinylaniline, if one water molecule is considered to take the role of the catalyst (pyridine). For the hydrolysis of 4-chlorophenyl isocyanate, however, a third-order dependence with respect to water concentration was reported (15). We therefore decided to explore the neutral hydrolysis of $N$-sulfinylaniline computationally to determine its mechanism and the number of water molecules involved.

\section{Computational details}

All geometry optimizations were performed with the Becke3 (18) - Lee, Young, and Parr (B3LYP) hybrid density functional (19) with the $6-31+\mathrm{G}(2 \mathrm{~d}, 2 \mathrm{p})$ basis set, using the
GAUSSIAN 98 suite of programs (20). This computational level best reproduces the observed geometry (X-ray analysis) of $N$-sulfinylaniline (17), and the basis set superposition error (BSSE) (21) consists of less than $0.7 \mathrm{kcal} \mathrm{mol}^{-1}$ for the ternary complexes (counterpoise $=3$, full geometry optimization). ${ }^{3}$ All structures were optimized without constraints. The complexes and their transition states were studied in the gas phase, as it was found in similar studies of the hydrolysis of isocyanates (16) and amides (22) that the inclusion of the solvent as a dielectric continuum only leads to a small decrease in the activation barrier. Vibrational frequencies and zero-point vibrational energies (ZPVE) were obtained at the preceding level of theory. The identity of each transition state was additionally verified using the intrinsic reaction coordinate (IRC) method $(23,24)$. The total $\left(E_{\text {tot }}\right)$ and ZPVE-corrected energies $\left(E_{\text {tot }}+\right.$ ZPVE), as well as the enthalpies of the complexes and their transition states, are summarized in Table 1. Throughout the paper, we will report only the enthalpy term at standard state, unless stated otherwise. We chose enthalpies over Gibbs free energies because an enthalpy is available (12) for comparison. Furthermore, the entropy contribution $(-T \Delta S)$ to the Gibbs free energy barrier, on average $5.8 \mathrm{kcal} \mathrm{mol}^{-1}$, is practically independent of the number of water molecules: it varies from 5.1 to $6.5 \mathrm{kcal} \mathrm{mol}^{-1}$ without apparent pattern for $1-5 \mathrm{H}_{2} \mathrm{O}$. Net atomic charges were obtained within the quantum theory of atoms in molecules (QTAIM) (25) with the AIMPAC module PROAIM (26). The natural bond orbital (NBO) program (NBO 3.1) (27) was used to study the charge transfer in the complexes (28).

\section{Results and discussion}

\section{Approach to the problem}

While the NSO group is commonly considered a heterocumulene and, from ${ }^{17} \mathrm{O}$ NMR (29) and computational (2) studies, the $\mathrm{S}=\mathrm{O}$ bond is best described as a four-electron bond not unlike the carbonyl $\mathrm{C}=\mathrm{O}$ bond, the electronic structure of $\mathrm{N}$-sulfinyl species can be represented as a set of resonance structures, shown in Scheme 2. Obviously, a change of substituent on nitrogen can change the reactivity of the NSO group; nevertheless, sulfur is the most positive centre and either nitrogen or oxygen is considered as the negative end of the bond dipole. We chose to study the computationally expensive $N$-sulfinylaniline (1) (instead of the more common approach to substitute the phenyl group for a smaller methyl group or the $\mathrm{H}$ atom (16)) because it is the only compound for which quantitative experimental data are available, and for comparison with the reactivities of aliphatic $N$-sulfinyl species in a subsequent paper. ${ }^{4}$

The calculated net atomic charges of $\mathbf{1}$ confirm the idea of sulfur being the most electrophilic atom of the NSO group (Fig. 1). Consequently, in a nucleophilic attack, the oxygen atom of the water molecule with a negative charge of

\footnotetext{
${ }^{3}$ We used the counterpoise correction method to verify the applicability of our chosen level of theory, and the BSSEs obtained with full geometry optimization for three structures are shown in Table 1. Our results of the study of other methods (HF and MP2) with various basis sets will be summarized elsewhere.

${ }^{4} \mathrm{~A}$ change in mechanism seems to be a common trait in the hydrolysis of NSO species with electron-donating substituents. For HNSO, the

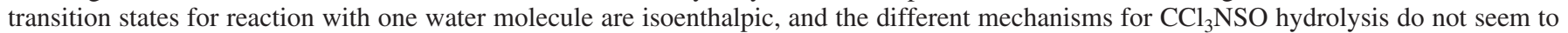
exhibit a dependence of preference on the number of water molecules. Manuscript in preparation.
} 
Table 1. Calculated total and zero-point corrected energies, as well as enthalpies at $298 \mathrm{~K}$ (au) of 1, water, the water dimer, and complexes 2-5 and their transition states for hydrolysis.

\begin{tabular}{|c|c|c|c|}
\hline Species & $E_{\text {tot }}$ & $E_{\text {tot }}+$ ZPVE & $H_{298}$ \\
\hline 1 & -759.811591 & -759.711892 & -759.703552 \\
\hline $\mathrm{H}_{2} \mathrm{O}$ & -76.441069 & -76.419706 & -76.415926 \\
\hline$\left(\mathrm{H}_{2} \mathrm{O}\right)_{2}$ & -152.890084 & -152.843858 & -152.837139 \\
\hline $2 \mathbf{a}$ & -836.255744 & -836.133041 & -836.120484 \\
\hline 2a-TS & -836.199402 & -836.079012 & -836.068877 \\
\hline 2b-TS & -836.193196 & -836.073030 & -836.062605 \\
\hline $3 \mathbf{a}$ & -912.710720 & $-912.562579(-912.561490)^{a}$ & -912.547481 \\
\hline 3a-TS & -912.665029 & -912.520710 & -912.508745 \\
\hline $3 \mathbf{b}$ & -912.708424 & $-912.560220(-912.559117)^{a}$ & -912.545030 \\
\hline 3b-TS & -912.661079 & -912.517559 & -912.505502 \\
\hline $4 \mathbf{a}$ & -989.164674 & -988.991597 & -988.973598 \\
\hline 4a-TS & -989.120910 & -988.952285 & -988.937976 \\
\hline $4 b$ & -989.162650 & $-988.989247(-988.987225)^{b}$ & -988.971435 \\
\hline 4b-TS & -989.120013 & -988.954007 & -988.939706 \\
\hline $4 c$ & -989.158246 & -988.985327 & -988.967235 \\
\hline 4c-TSa & -989.115485 & -988.946429 & -988.931412 \\
\hline 4c-TSb & -989.112714 & -988.943772 & -988.928953 \\
\hline $5 c$ & -1142.068493 & -1141.844795 & -1141.821378 \\
\hline $5 c-T S b$ & -1142.028754 & -1141.811961 & -1141.792257 \\
\hline
\end{tabular}

Note: Values in parentheses give counterpoise $(\mathrm{CP})$ corrected energies.

${ }^{a} \mathrm{CP}=3$ and BSSE $=0.7 \mathrm{kcal} \mathrm{mol}^{-1}$.

${ }^{b} \mathrm{CP}=4$ and $\mathrm{BSSE}=1.3 \mathrm{kcal} \mathrm{mol}^{-1}$.

Scheme 2.

$$
\mathrm{R}-\ddot{\mathrm{N}}=\ddot{\mathrm{S}}=\ddot{\mathrm{O}} \longleftrightarrow \mathrm{R}-\ddot{\overline{\mathrm{N}}}-\stackrel{+}{\ddot{\mathrm{S}}}=\ddot{\mathrm{O}} \longleftrightarrow \mathrm{R}-\ddot{\mathrm{N}}=\stackrel{+}{\mathrm{S}}-\ddot{\overline{\mathrm{O}}}:
$$

Fig. 1. Selected calculated charges of atoms of interest in $\mathrm{N}$ sulfinylaniline (1), water, and the water dimer.

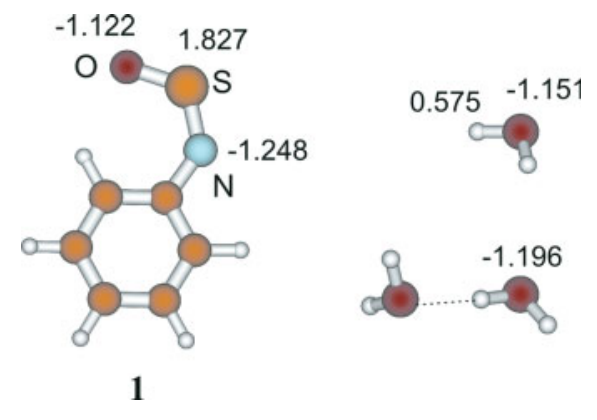

-1.151 au is expected to attack the sulfur atom. A proton can then be transferred to either the oxygen (attack across the $\mathrm{S}=\mathrm{O}$ bond, path a) or the nitrogen (attack across the $\mathrm{N}=\mathrm{S}$ bond, path b) atom of the NSO group (Scheme 3), similar to hydrogen isocyanate hydrolysis (16).

Reaction across the $\mathrm{S}=\mathrm{O}$ bond includes two steps, the protonation of oxygen with formation of $\mathrm{N}$-phenylsulfurimidic acid and a subsequent 1,3-hydrogen shift to form the intermediate $N$-phenylsulfinamic acid, which decomposes with formation of the final products, aniline and sulfur dioxide. Reaction across the $\mathrm{N}=\mathrm{S}$ bond, on the other hand, is a onestep process that directly yields $N$-phenylsulfinamic acid.

Structures from the interaction across the $\mathrm{S}=\mathrm{O}$ bond are denoted with the letter "a", those from the interaction across
Scheme 3.

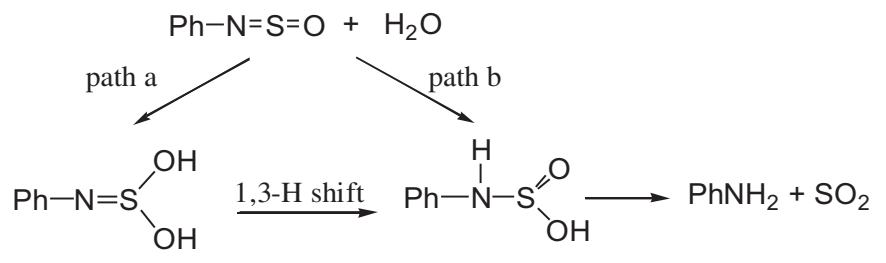

the $\mathrm{N}=\mathrm{S}$ bond with the letter "b". Structures with interactions across both $\mathrm{S}=\mathrm{O}$ and $\mathrm{N}=\mathrm{S}$ bonds are given the letter "c". The subscript " $w$ " is used for the designation of atoms that belong to water molecules. In the description of complexes with multiple water molecules, " $\mathrm{H}_{\mathrm{w} 1}$ " determines a hydrogen atom of the water molecule that interacts with the oxygen atom of the $\mathrm{S}=\mathrm{O}$ bond, and " $\mathrm{H}_{\mathrm{w} 2}$ ", a hydrogen atom of the water molecule that interacts with the nitrogen atom of the $\mathrm{N}=\mathrm{S}$ bond.

In the following, we examine how the preference for reaction across the $\mathrm{N}=\mathrm{S}$ or $\mathrm{S}=\mathrm{O}$ bond depends on the number of water molecules participating in the reaction. The complete reaction coordinate for the hydrolysis of $\mathbf{1}$ is presented for the participation of two water molecules.

\section{Reaction of $\boldsymbol{N}$-sulfinylaniline with one water molecule}

Interaction with one water molecule is the simplest model in the study of the hydrolysis of $N$-sulfinylaniline (1). Even though the formation of a prereaction complex usually precedes the reaction, we were only able to locate complex $\mathbf{2 a}$ with water situated on top of the $\mathrm{S}=\mathrm{O}$ bond (Fig. 2). Our search for $\mathbf{2 b}$ with water on top of the $\mathrm{N}=\mathrm{S}$ bond produced numerous hydrogen-bonded complexes, but there does not 
Table 2. Selected geometrical parameters (distances in $\mathrm{pm}$, torsional angles in degrees) of $N$-sulfinylaniline (1) and its complexes with one, two, three, and five water molecules (2-5).

\begin{tabular}{|c|c|c|c|c|c|c|c|c|}
\hline & 1 & $2 a$ & $3 \mathbf{a}$ & $3 b$ & $4 a$ & $4 b$ & $4 c$ & $5 c$ \\
\hline $\mathrm{SO}$ & 148.1 & $\begin{array}{l}148.7 \\
(+0.6)\end{array}$ & $\begin{array}{r}149.2 \\
(+1.1)\end{array}$ & $\begin{array}{l}147.7 \\
(-0.4)\end{array}$ & $\begin{array}{l}149.2 \\
(+1.1)\end{array}$ & $\begin{array}{l}147.4 \\
(-0.7)\end{array}$ & $\begin{array}{l}148.7 \\
(+0.6)\end{array}$ & $\begin{array}{l}148.5 \\
(+0.4)\end{array}$ \\
\hline NS & 153.4 & $\begin{array}{l}153.0 \\
(-0.4)\end{array}$ & $\begin{array}{l}152.8 \\
(-0.6)\end{array}$ & $\begin{array}{l}154.4 \\
(+1.0)\end{array}$ & $\begin{array}{l}152.7 \\
(-0.7)\end{array}$ & $\begin{array}{l}154.3 \\
(+0.9)\end{array}$ & $\begin{array}{l}153.5 \\
(+0.1)\end{array}$ & $\begin{array}{l}153.8 \\
(+0.4)\end{array}$ \\
\hline $\mathrm{S} \cdots \mathrm{O}_{\mathrm{w}}$ & & 319.0 & 314.6 & 377.9 & 297.9 & 296.2 & 284.0 & 271.8 \\
\hline $\mathrm{O} \cdots \mathrm{H}_{\mathrm{w} 1}$ & & 240.4 & 192.0 & & 195.9 & & 197.6 & 189.2 \\
\hline $\mathrm{N} \cdots \mathrm{H}_{\mathrm{w} 2}$ & & & & 199.4 & & 194.7 & 236.4 & 196.9 \\
\hline $\mathrm{NSOO}_{\mathrm{w}}$ & & 101.9 & 109.8 & 131.2 & 105.0 & 107.0 & 106.8 & 109.3 \\
\hline $\mathrm{NSOH}_{\mathrm{w} 1}$ & & 104.3 & 116.8 & & 128.1 & & 95.8 & 103.8 \\
\hline $\mathrm{OSNH}_{\mathrm{w} 2}$ & & & & 177.2 & & 170.2 & 122.0 & 171.8 \\
\hline
\end{tabular}

Note: Values in parentheses show the change in the distances upon complexation with respect to 1.

Fig. 2. Optimized complex 2a for the interaction of $\mathbf{1}$ with one water molecule, and transition states $\mathbf{2 a}$-TS and $\mathbf{2 b}$-TS for the addition of water across the $\mathrm{S}=\mathrm{O}$ and the $\mathrm{N}=\mathrm{S}$ bond of $\mathbf{1}$, respectively. Weak interactions in the transition states are given with solid lines.

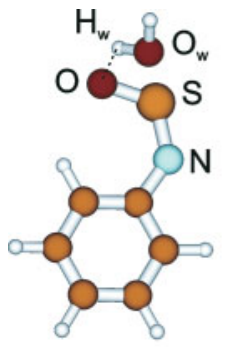

$\mathbf{2 a}$

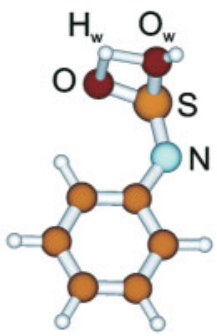

2a-TS

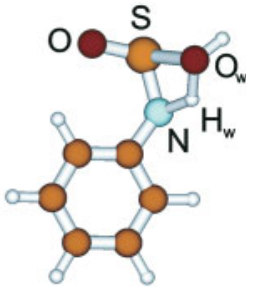

2b-TS seem to be a stationary point on the potential energy surface for $\mathbf{2 b} .^{5}$

The intermolecular distance between the sulfur atom and the oxygen atom of water $\left(\mathrm{O}_{\mathrm{w}}\right)$ in $\mathbf{2 a}$ is $319.0 \mathrm{pm}$ (Table 2), with the water molecule forming a close to perpendicular alignment with the plane of $\mathbf{1}$ (the $\mathrm{NSOO}_{\mathrm{w}}$ dihedral angle is $101.9^{\circ}$ ). Even though this distance is less than $325.0 \mathrm{pm}$, which is the accepted value for the sum of the van der Waals radii of oxygen and sulfur atoms (30), according to an analysis of the electron density within QTAIM, there is no interaction between these atoms. ${ }^{5}$ The complex $\mathbf{2 a}$ is stabilized by a hydrogen bond with an $\mathrm{O} \cdots \mathrm{H}_{\mathrm{w}}$ distance of $240.4 \mathrm{pm}$ and an $\mathrm{OH}_{\mathrm{w}} \mathrm{O}_{\mathrm{w}}$ angle of $130.8^{\circ}$. This nonideal hydrogen bond geometry is in good agreement with the small stabilization energy of $0.6 \mathrm{kcal} \mathrm{mol}^{-1}$ upon complex formation (Table 3). The perpendicular attack on sulfur is in stark contrast to the in-plane attack of water on the carbon atom in $\mathrm{HNCO}$ (16).

The activation enthalpy for the reaction of $\mathbf{1}$ with one water molecule is very high with 31.8 and $35.7 \mathrm{kcal} \mathrm{mol}^{-1}$ for transition states 2a-TS and $\mathbf{2 b - T S}$, respectively (Fig. 2 and Table 3 ). The barriers are calculated from the enthalpies of the reagents for lack of complex $\mathbf{2} \mathbf{b}$ as a reference. The reaction across the $\mathrm{S}=\mathrm{O}$ bond (path a) is favoured by $3.9 \mathrm{kcal} \mathrm{mol}^{-1}$.

\section{Reaction of $N$-sulfinylaniline with two water molecules}

Introduction of a second water molecule allows the formation of a water dimer, which increases the nucleophilic properties of water towards the electrophilic sulfur. The negative charge on the oxygen atom of the original water molecule is increased by 0.045 au from -1.151 au in the monomer to -1.196 au in the dimer (Fig. 1). Unlike in the interaction with one water molecule, both prereaction complexes $\mathbf{3 a}$ and 3b were located (Fig. 3). This is also different from HNCO hydrolysis in that prereaction complexes of HNCO with water chains (dimers and trimers) were not found (16). Selected geometrical parameters of $\mathbf{3 a}$ and $\mathbf{3} \mathbf{b}$ are shown in Table 2. Stabilization in both complexes is achieved through an $\mathrm{S} \cdots \mathrm{O}_{\mathrm{w}}$ interaction along with hydrogen bond formation. The $\mathrm{S} \cdots \mathrm{O}_{\mathrm{w}}$ interaction is mostly due to the electrostatic attraction between sulfur and water oxygen atoms, combined with some charge transfer from the lone pair of $\mathrm{O}_{\mathrm{w}}$ into the antibonding orbital of the $\mathrm{N}=\mathrm{S}$ bond $\left(\pi_{\mathrm{N}=\mathrm{S}}^{*}\right)$, found for 3a from an NBO analysis. ${ }^{5}$ As expected, complexation across the $\mathrm{S}=\mathrm{O}$ bond primarily affects the $\mathrm{S}-\mathrm{O}$ bond length, and complexation across the $\mathrm{N}=\mathrm{S}$ bond mainly influences the $\mathrm{N}-\mathrm{S}$ bond length. The lengthening of both bonds in their respective complexes to a similar degree coincides with the contraction of the second cumulated double bond (the changes in bond lengths from $\mathbf{1}$ are given in Table 2 for ease of comparison). But while $\mathbf{3 a}$ exhibits the close to perpendicular arrangement between the plane of $\mathbf{1}$ and the water molecule complexed to sulfur that we also observed for $\mathbf{2 a}$, there is a much larger deviation from $90^{\circ}$ found in $\mathbf{3 b}$. In addition, the $\mathrm{S} \cdots \mathrm{O}_{\mathrm{w}}$ intermolecular distance in $\mathbf{3 b}$ is significantly larger than that in 3a, suggesting a nonideal arrangement of its constituent fragments. These findings are nicely in accord with those for complexation with one water molecule and offer an explanation as to why $\mathbf{2} \mathbf{b}$ could not be located. The requirements of a perpendicular attack of $\mathrm{O}_{\mathrm{w}}$ on sulfur and an in-plane $\mathrm{N} \cdots \mathrm{H}_{\mathrm{w}} \mathrm{O}$ hydrogen bond (the $\mathrm{OSNH}_{\mathrm{w} 2}$ dihedral in $\mathbf{3 b}$ is close to $180^{\circ}$, Table 2 ) prevent the formation of $\mathbf{2} \mathbf{b}$ and render $\mathbf{3 b}$ somewhat strained. This interpreta-

\footnotetext{
${ }^{5}$ A detailed analysis of hydrogen bonding and other weak interactions in the complexes and their transition states will be presented elsewhere. Manuscript in preparation.
} 
Table 3. Enthalpies $\left(\mathrm{kcal} \mathrm{mol}^{-1}\right.$ ) of complex formation and of activation at $298 \mathrm{~K}$ for $\mathbf{1}$ with one, two, three, and five water molecules.

\begin{tabular}{|c|c|c|c|c|c|c|c|c|}
\hline \multirow[b]{2}{*}{$n \mathrm{H}_{2} \mathrm{O}$} & \multicolumn{4}{|c|}{ Across $S=0$} & \multicolumn{4}{|c|}{ Across $\mathrm{N}=\mathrm{S}$} \\
\hline & Complex & $-\Delta H_{\text {bind }}$ & $\mathrm{TS}$ & $\Delta H^{\ddagger}$ & Complex & $-\Delta H_{\text {bind }}$ & $\mathrm{TS}$ & $\Delta H^{\ddagger}$ \\
\hline 1 & $\mathbf{2 a}$ & 0.6 & 2a-TS & $\begin{array}{l}32.4 \\
(31.8)^{b}\end{array}$ & $2 \mathbf{b}$ & $a$ & 2b-TS & $\overline{(35.7)^{b}}$ \\
\hline 2 & $3 \mathbf{a}$ & 7.6 & 3a-TS & 24.3 & $3 b$ & 6.0 & 3b-TS & 24.8 \\
\hline 3 & $4 \mathbf{a}$ & 14.0 & 4a-TS & 22.4 & $4 b$ & 12.6 & $4 b-T S$ & 19.9 \\
\hline & $4 c$ & 10.0 & 4c-TSa & 22.5 & $4 c$ & 10.0 & 4c-TSb & 24.0 \\
\hline 5 & $5 c$ & 24.0 & & & $5 c$ & 24.0 & 5c-TSb & 18.3 \\
\hline
\end{tabular}

Fig. 3. Optimized complexes $\mathbf{3 a}$ and $\mathbf{3 b}$ for the interaction of $\mathbf{1}$ with the water dimer, and transition states $\mathbf{3 a - T S}$ and $\mathbf{3 b}$-TS. Weak interactions in the transition states are given with solid lines.

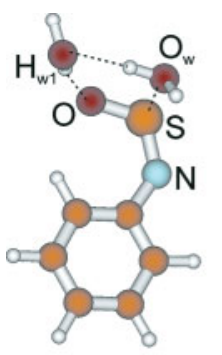

3a

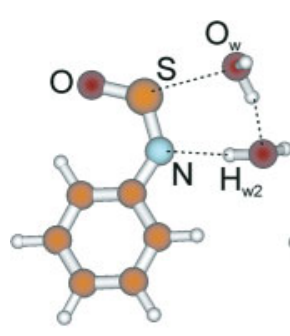

$3 \mathbf{b}$

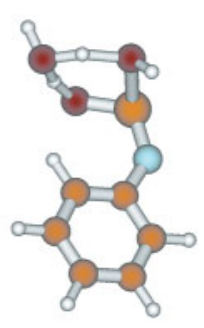

3a-TS

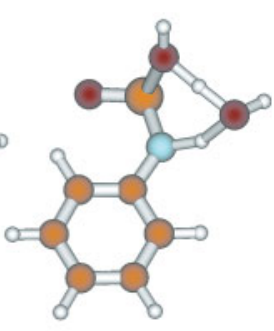

3b-TS tion is supported by the relative energies of $\mathbf{3 a}$ and $\mathbf{3 b}$, with 3b less stable by $1.6 \mathrm{kcal} \mathrm{mol}^{-1}$. The formation of sixmembered cycles reduces the strain that exists in the fourmembered cycles of transition states $\mathbf{2 a - T S}$ and $\mathbf{2 b}$ - TS in the reaction of $\mathbf{1}$ with one water molecule. The full reaction coordinates for the reaction of $\mathrm{N}$-sulfinylaniline (1) with two water molecules are given in Fig. 4 for water addition across the $\mathrm{S}=\mathrm{O}$ bond (path a) and in Fig. 5 for addition across the $\mathrm{N}=\mathrm{S}$ bond (path $\mathrm{b}$ ).

The formation of $\mathbf{3 a}$ is favourable by $7.6 \mathrm{kcal} \mathrm{mol}^{-1}$ with a stabilization of $4.3 \mathrm{kcal} \mathrm{mol}^{-1}$ in addition to the $3.3 \mathrm{kcal}$ $\mathrm{mol}^{-1}$ of energy gain due to water dimer formation. The experimental enthalpy of association in the water dimer was found to be $-3.59 \pm 0.5 \mathrm{kcal} \mathrm{mol}^{-1}$ at $373 \mathrm{~K}(31)$. As was proposed (12), hydration of sulfur with protonation of oxygen of $\mathbf{1}$ is indeed the rate-determining step of the reaction. The activation enthalpy is $24.3 \mathrm{kcal} \mathrm{mol}^{-1}$, a value that includes $2.3 \mathrm{kcal} \mathrm{mol}^{-1}$ because of the loss of planarity in $\mathbf{1}(\mathbf{1}$ in $\mathbf{3 a}$ is planar whereas in both the complex $\mathbf{3} \mathbf{a}^{\prime}$ and the transition state 3a-TS, CCNS and CNSO torsional angles are $6.1^{\circ}$ and $23.6^{\circ}$, respectively). The torsions allow a decrease of the $\mathrm{S} \cdots \mathrm{O}_{\mathrm{w}}$ interatomic distance from $314.6 \mathrm{pm}$ in $\mathbf{3 a}$ to $299.4 \mathrm{pm}$ in $\mathbf{3} \mathbf{a}^{\prime}$, and this shortening of about $15 \mathrm{pm}$ increases the strength of the interaction and facilitates the hydration of sulfur. Further along the reaction path, the water molecule in the primary reaction product (the complex of $\mathrm{N}$-phenylsulfurimidic acid and water) changes its orientation, which allows it to abstract a proton from one hydroxyl group of $N$-phenylsulfurimidic acid and simultaneously protonate the acid's nitrogen atom. This "water-assisted" 1,3-hydrogen shift ${ }^{6}$ requires only $1.8 \mathrm{kcal} \mathrm{mol}^{-1}$ and yields the complex of $\mathrm{N}$-phenylsulfinamic acid and water in which the orientation of the water molecule cannot facilitate the protonation of nitrogen. Thus, the unassisted decomposition of $N$-phenylsulfinamic acid into the complex of aniline, sulfur dioxide, and water requires the large activation enthalpy of $15.9 \mathrm{kcal} \mathrm{mol}^{-1}$. We find exactly the same value, $15.9 \mathrm{kcal} \mathrm{mol}^{-1}$, for the enthalpy of activation for the decomposition of $\mathrm{N}$-phenylsulfinamic acid in the absence of any water. ${ }^{6}$

The formation of $\mathbf{3 b}$ is less favourable than that of $\mathbf{3 a}$, as previously discussed, and only shows a stabilization of $2.7 \mathrm{kcal} \mathrm{mol}^{-1}$ in addition to the stabilization from water dimer formation (Fig. 5). The reaction of the water dimer with 1 again is the rate-determining step and an activation enthalpy of $24.8 \mathrm{kcal} \mathrm{mol}^{-1}$ is required, which is only $0.5 \mathrm{kcal} \mathrm{mol}^{-1}$ higher than (and therefore comparable with) that for the reaction across the $\mathrm{S}=\mathrm{O}$ bond. As in Fig. 4, this activation barrier includes $1.8 \mathrm{kcal} \mathrm{mol}^{-1}$ because of the torsion of the NSO group out of the plane of the aromatic ring (the CCNS and CNSO torsional angles of $46.0^{\circ}$ and $7.9^{\circ}$, respectively, are similar in the complex $\mathbf{3} \mathbf{b}^{\prime}$ and in the transition state $\mathbf{3 b} \mathbf{b} \mathbf{T S})$. As in $\mathbf{3} \mathbf{a}^{\prime}$, the $\mathrm{S}^{\prime} \cdot \mathrm{O}_{\mathrm{w}}$ interaction is strengthened through a decrease in the intermolecular distance by $37 \mathrm{pm}$, from $377.9 \mathrm{pm}$ in $\mathbf{3 b}$ to $340.9 \mathrm{pm}$ in $\mathbf{3} \mathbf{b}^{\prime}$. Unlike 3a-TS in Fig. 4, 3b-TS in Fig. 5 directly yields the

\footnotetext{
${ }^{6} \mathrm{We}$, of course, only present a subset of possibilities of hydrogen bond formation on the potential energy surface for reaction of $N$ sulfinylaniline (1) with two water molecules. We believe that the chosen structures explain the formation of the final products and in some cases show the importance of the explicit treatment of water along the reaction pathway. Thus, we exclude, for example, the nonassisted 1,3-hydrogen shift in $N$-phenylsulfurimidic acid.
} 
Fig. 4. Enthalpy profile for the reaction of $\mathbf{1}$ with two water molecules (path a), attack across the $\mathrm{S}=\mathrm{O}$ bond.

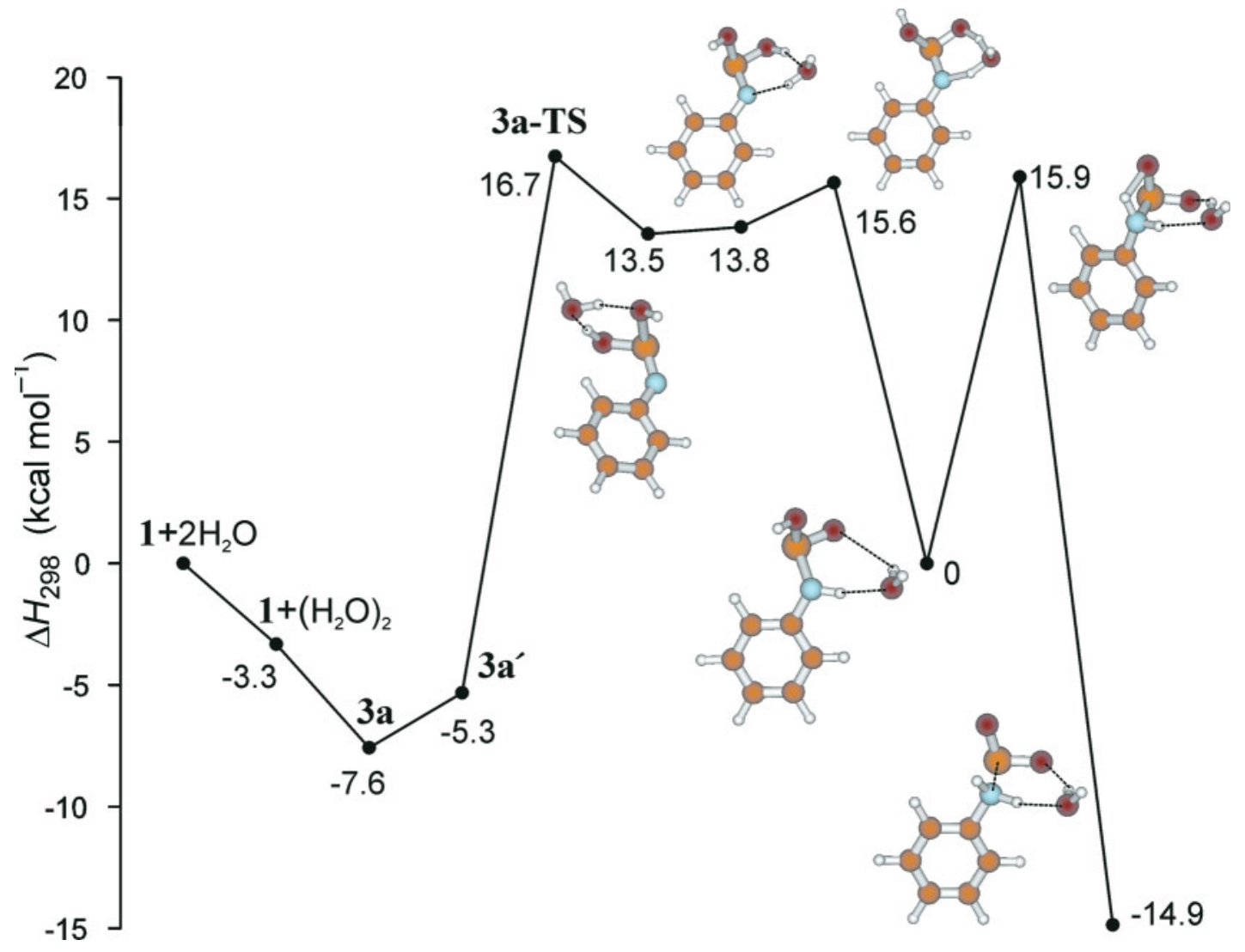

complex of $N$-phenylsulfinamic acid and water. Hydrogen bonding to the hydroxyl group of $N$-phenylsulfinamic acid allows for a reorientation of the water molecule that moves it into the ideal position for protonation of the nitrogen atom and facilitates the decomposition of the acid. In this waterassisted decomposition the activation barrier is decreased with respect to the nonassisted barrier in Fig. 4 by more than $10 \mathrm{kcal} \mathrm{mol}^{-1}$ to a mere $5.5 \mathrm{kcal} \mathrm{mol}^{-1}$. This finding, as well as the assistance of water in the 1,3-hydrogen shift, which was discussed in the previous mechanism (path a, Fig. 4), demonstrates the importance of the explicit treatment of water molecules in these hydrolysis reactions, a conclusion that was drawn earlier in amide $(32,33)$ and isocyanate hydrolysis (16).

The increase in the number of water molecules from one to two allows a decrease in the activation barriers for the hydrolysis reaction of approximately 8-11 kcal mol ${ }^{-1}$ (from 32.4 in $\mathbf{2 a - T S}$ to $24.3 \mathrm{kcal} \mathrm{mol}^{-1}$ in $\mathbf{3 a - T S}$, and from $35.7^{7}$ in $\mathbf{2 b}$-TS to $24.8 \mathrm{kcal} \mathrm{mol}^{-1}$ in $\mathbf{3 b} \mathbf{b}$-TS). This is at least partially due to the relief of strain on going from fourmembered cycles in $\mathbf{2 a - T S}$ and $\mathbf{2 b}$-TS to the six-membered cycles in 3a-TS and $\mathbf{3 b}$-TS, as was mentioned earlier. The $\mathrm{N}=\mathrm{S}$ bond demonstrates a higher sensitivity to this effect because the hydroxyl group of the second water molecule now approaches $\mathbf{1}$ in the NSO plane (with a $\mathrm{OSNH}_{\mathrm{w} 2}$ torsional angle of $177.2^{\circ}$, Table 2 ), where the nitrogen lone pair lies, confirming the idea of donor-acceptor directionality in hydrogen bond formation.

Our finding about the almost equal probability of both mechanisms owing to activation barriers of $24.3 \mathrm{kcal} \mathrm{mol}^{-1}$ for path a and $24.8 \mathrm{kcal} \mathrm{mol}^{-1}$ for path $\mathrm{b}$ seems quite different from the results for HNCO hydrolysis (16). Calculations in the gas phase and in a solvent field based on the polarizable continuum model (PCM) with MP2/6-31G(d,p), along with other methods, have shown that even though two water molecules are important for HNCO hydrolysis, in all cases studied (the presence of one, two, and three water molecules was considered), reaction across the $\mathrm{N}=\mathrm{C}$ bond is favoured. With two water molecules, for example, the activation energy decreases from $28 \mathrm{kcal} \mathrm{mol}^{-1}$ for reaction across the $\mathrm{C}=\mathrm{O}$ bond to $11 \mathrm{kcal} \mathrm{mol}^{-1}$ for reaction across the $\mathrm{N}=\mathrm{C}$ bond (values reported in the paper are $E_{\text {tot }}+\mathrm{ZPVE}$, given in $\mathrm{kJ} \mathrm{mol}^{-1}$, and based on the corrected energies of the reactants). In the presence of a solvent field this difference becomes much smaller though, $15 \mathrm{kcal}^{\mathrm{mol}^{-1}}$ for reaction across $\mathrm{C}=\mathrm{O}$ to $18 \mathrm{kcal} \mathrm{mol}^{-1}$ for reaction across $\mathrm{N}=\mathrm{C}$ (single point energy calculations on the gas-phase optimized geometries). To be able to compare results more directly, we also report ZPVE corrected energies in Table 1. From these, we obtain an activation energy of $19.2 \mathrm{kcal} \mathrm{mol}^{-1}$ for reaction across $\mathrm{S}=\mathrm{O}$ and $21.1 \mathrm{kcal} \mathrm{mol}^{-1}$ for that across $\mathrm{N}=\mathrm{S}$, both based on the corrected energies for $\mathbf{1}$ and two water mole-

\footnotetext{
${ }^{7}$ As previously discussed, this value is not based on the enthalpy of the prereaction complex, but rather on the enthalpies of the reactants, $\mathbf{1}$ and water.
} 
Fig. 5. Enthalpy profile for the reaction of $\mathbf{1}$ with two water molecules (path b), attack across the $\mathrm{N}=\mathrm{S}$ bond.

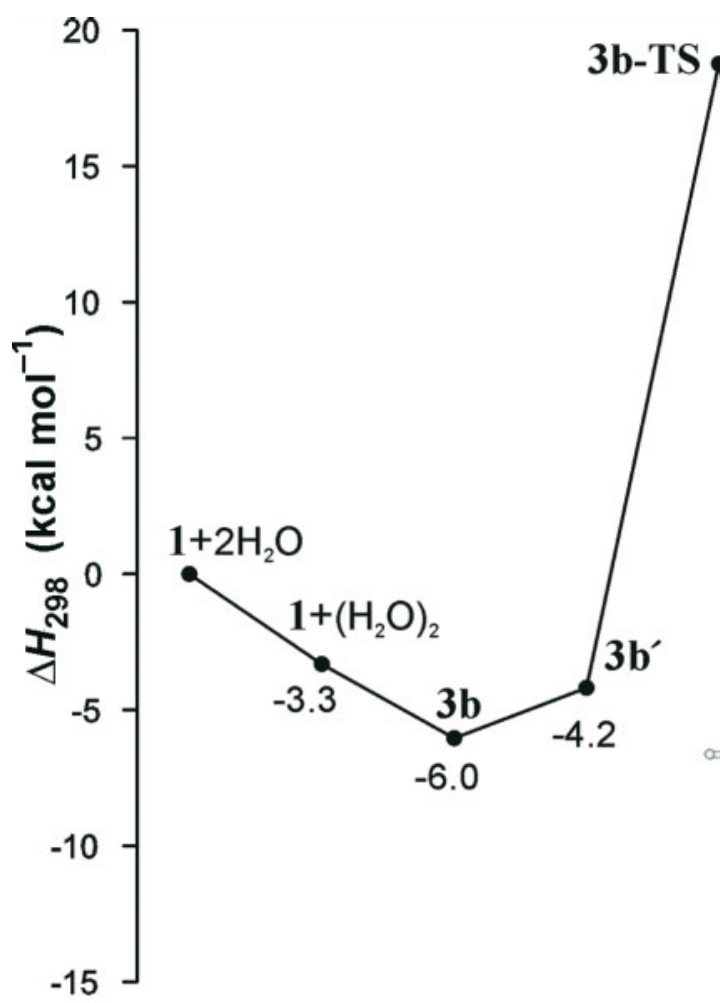

cules. Obviously, the direct comparison is limited by the different substituents (phenyl in $\mathbf{1}$ and hydrogen in HNCO), and further analysis of the difference between RNSO and RNCO hydrolysis will only be reported in our forthcoming paper on substituent effects in the reactivity of NSO species. $^{4}$

\section{Reaction of $N$-sulfinylaniline with three and five water molecules}

Compared to the reaction of $N$-sulfinylaniline with one and two water molecules, water trimer complexation to $\mathbf{1}$ in 4a and 4b (Fig. 6) further increases the flexibility of the systems owing to formation of eight-membered cycles. As can be seen from Table 2, the lengths and, consequently, the strengths of the $\mathrm{S}=\mathrm{O}$ and $\mathrm{N}=\mathrm{S}$ bonds do not differ much in complexes of 1 with two $(\mathbf{3 a}, \mathbf{3 b})$ and three $(\mathbf{4 a}, \mathbf{4 b})$ water molecules. But inclusion of the third water molecule significantly strengthens the weak $\mathrm{S} \cdots \mathrm{O}_{\mathrm{w}}$ interaction. The effect is especially pronounced for complexation of the water trimer across the $\mathrm{N}=\mathrm{S}$ bond. The $\mathrm{S} \cdots \mathrm{O}_{\mathrm{w}}$ intermolecular distance decreases by 81.7 pm, from 377.9 pm in $\mathbf{3 b}$ to $296.2 \mathrm{pm}$ in $\mathbf{4 b}$ (Table 2). For complexation towards the $\mathrm{S}=\mathrm{O}$ bond this effect is less pronounced, but still important, as the $\mathrm{S} \cdots \mathrm{O}_{\mathrm{w}}$ distance decreases by $16.7 \mathrm{pm}$ going from 3a to $\mathbf{4 a}$. Along with this, a contraction of the $\mathrm{N} \cdots \mathrm{H}_{\mathrm{w} 2}$ hydrogen bond by $4.7 \mathrm{pm}$ is found going from $\mathbf{3 b}$ to $\mathbf{4 b}$. In contrast, comparing $\mathbf{3 a}$ and 4a, the $\mathrm{O} \cdots \mathrm{H}_{\mathrm{w} 1}$ hydrogen bond distance increases by $3.4 \mathrm{pm}$.

The strengthening of the $\mathrm{S} \cdots \mathrm{O}_{\mathrm{w}}$ intermolecular interaction in complexes $\mathbf{4 a}$ and $\mathbf{4 b}$ further decreases the activation barrier for hydrolysis by approximately $2-5 \mathrm{kcal} \mathrm{mol}^{-1}$ for the two pathways (from 24.3 in $\mathbf{3 a - T S}$ to $22.4 \mathrm{kcal} \mathrm{mol}^{-1}$ in $\mathbf{4 a -}$ TS for the reaction across the $\mathrm{S}=\mathrm{O}$ bond, and from 24.8 in

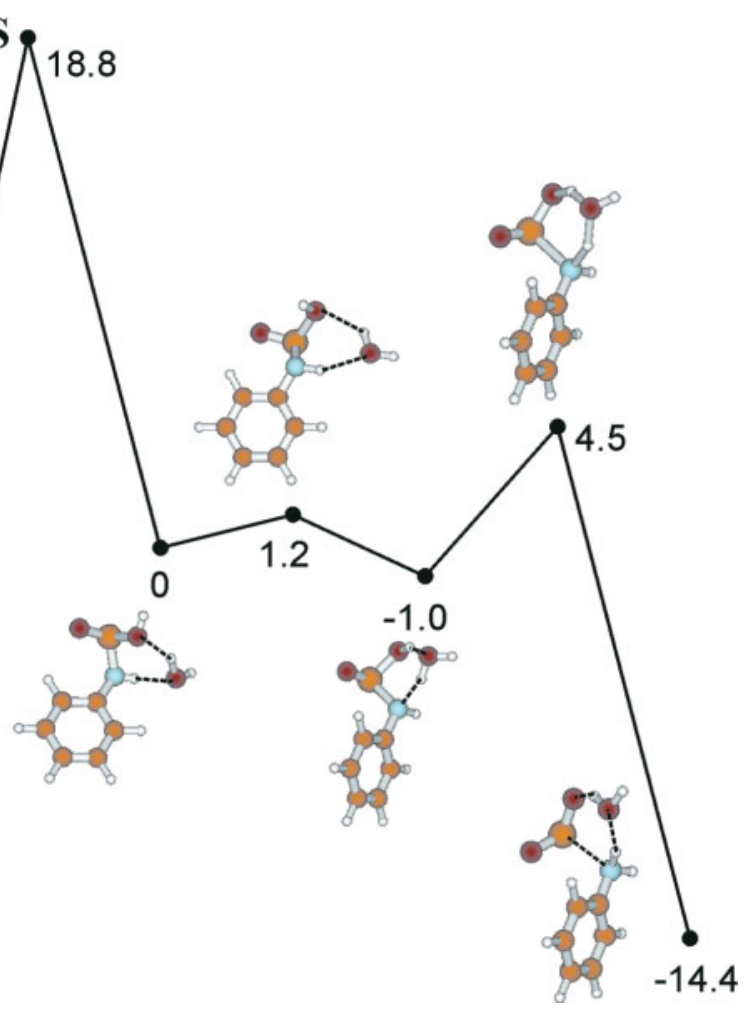

3b-TS to $19.9 \mathrm{kcal} \mathrm{mol}^{-1}$ in $\mathbf{4 b}$ - $\mathbf{T S}$ for the reaction across the $\mathrm{N}=\mathrm{S}$ bond, Table 3 ). The one-step mechanism, reaction across the $\mathrm{N}=\mathrm{S}$ bond, is now favoured by $2.5 \mathrm{kcal} \mathrm{mol}^{-1}$, as two requirements, "perpendicular" attack on sulfur $\left(\mathrm{NSOO}_{\mathrm{w}}\right.$ torsional angle $107.0^{\circ}$ ) and in-plane protonation of nitrogen $\left(\mathrm{OSNH}_{\mathrm{w} 2}\right.$ torsional angle $\left.170.2^{\circ}\right)$, are fulfilled without apparent strain.

The two different attacks on the NSO group are combined in $\mathbf{4 c}$, where hydrogen bonding to both nitrogen and oxygen atoms of the NSO group assists in the strengthening of the $\mathrm{S} \cdots \mathrm{O}_{\mathrm{w}}$ interaction, which is 12.2 and $13.9 \mathrm{pm}$ shorter than in $\mathbf{4 a}$ and $\mathbf{4 b}$, respectively (Table 2). But both hydrogenbonding interactions are weaker in $\mathbf{4} \mathbf{c}$ than in either $\mathbf{4 a}$ or 4b. The increase in the $\mathrm{O} \cdots \mathrm{H}_{\mathrm{w} 1}$ distance in $\mathbf{4 c}$ from $\mathbf{4 a}$ by $1.7 \mathrm{pm}$ is considered to be insignificant, and this is reflected in the enthalpy barrier of $22.5 \mathrm{kcal} \mathrm{mol}^{-1}$ for reaction via $4 \mathrm{c}$ TSa, which is similar to the activation enthalpy of $22.4 \mathrm{kcal}$ $\mathrm{mol}^{-1}$ for $4 \mathrm{a}-\mathbf{T S}$. In contrast, the increase in the $\mathrm{N} \cdots \mathrm{H}_{\mathrm{w} 2}$ intermolecular distance in $\mathbf{4 c}$ from $\mathbf{4 b}$ by $41.7 \mathrm{pm}$, together with a less favourable $\mathrm{OSNH}_{\mathrm{w} 2}$ dihedral angle of $122.0^{\circ}$ in $\mathbf{4 c}$, contributes to $\mathbf{4 c - T S b}$ being less stable than $\mathbf{4 b}$-TS and increases the activation barrier by $4.1 \mathrm{kcal} \mathrm{mol}^{-1}$.

As can be seen from Figs. 3 and 6, the structures for 4cTSa and 4c-TSb are very similar to those obtained for reaction of $\mathbf{1}$ with two water molecules (3a-TS and 3b-TS). The third water molecule in complex $\mathbf{4 c}$, and consequently in $\mathbf{4 c -}$ TS4a and 4c-TSb, might be seen as a bystander that does not directly react with $\mathbf{1}$, yet it participates through hydrogen bond formation, which weakens both $\mathrm{S}=\mathrm{O}$ and $\mathrm{N}=\mathrm{S}$ bonds (Table 2). The elongation of these bonds from those in $\mathbf{1}$ is less efficient than in $\mathbf{3 a}$ and $\mathbf{3 b}$ and consists of $0.6 \mathrm{pm}$ for the $\mathrm{S}=\mathrm{O}$ and $0.1 \mathrm{pm}$ for the $\mathrm{N}=\mathrm{S}$ bond in $\mathbf{4 c}$, but the weak- 
Fig. 6. Optimized structures $\mathbf{4 a - 4 c}$ and $\mathbf{5 c}$ for the interaction of $\mathbf{1}$ with three and five water molecules, and transition states $\mathbf{4 a - T S}, \mathbf{4 b}-$ TS, 4c-TSa, 4c-TSb, and 5c-TSb for hydrolysis.

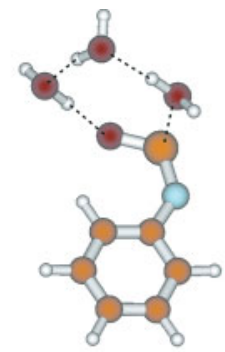

$4 a$

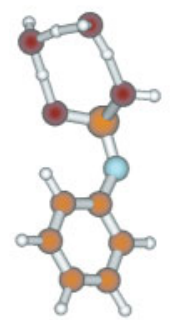

4a-TS

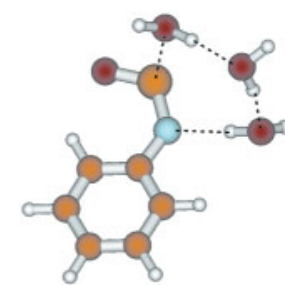

$4 b$

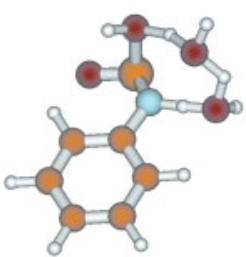

4b-TS

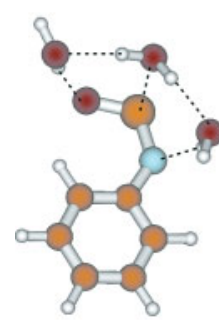

$4 c$

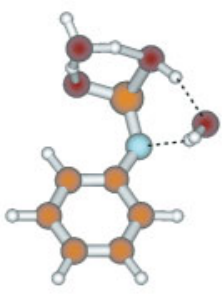

4c-TSa

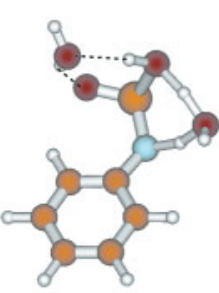

4c-TSb

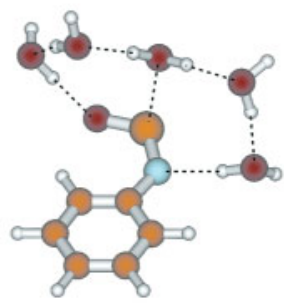

$5 c$

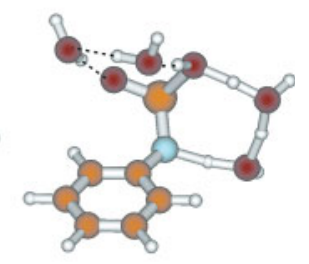

5c-TSb ening of the bonds of the NSO group is accompanied by a significant shortening of the $\mathrm{S} \cdots \mathrm{O}_{\mathrm{w}}$ intermolecular distance in $\mathbf{4 c}$ by 30.6 and 93.9 pm from $\mathbf{3 a}$ and $\mathbf{3 b}$, respectively, which facilitates hydrolysis. This is reflected in a decrease in the activation barrier (by $2.2 \mathrm{kcal} \mathrm{mol}^{-1}$ in $\mathbf{4 c}$-TSa compared to $\mathbf{3 a - T S}$, and by $0.8 \mathrm{kcal} \mathrm{mol}^{-1}$ in $\mathbf{4} \mathbf{c}-\mathbf{T S b}$ compared to $\mathbf{3 b} \mathbf{b}$ TS).

Complex 5c (Fig. 6) represents the combination of $\mathbf{4 a}, \mathbf{4 b}$, and $\mathbf{4 c}$ in that both points of attack to the NSO group are connected as in $\mathbf{4 c}$, but the strain in $\mathbf{4 c}$ is removed by the inclusion of water molecules, similar to $\mathbf{4 a}$ and $\mathbf{4 b}$. The $\mathrm{S} \cdots \mathrm{O}_{\mathrm{w}}$ intermolecular distance of $271.8 \mathrm{pm}$ in $\mathbf{5 c}$ is found to be the shortest among all complexes studied. The $\mathrm{O} \cdots \mathrm{H}_{\mathrm{w} 1}$ distance in $\mathbf{5 c}$ is shorter than in both $\mathbf{4 a}$ and $\mathbf{4 c}$, whereas the $\mathrm{N} \cdots \mathrm{H}_{\mathrm{w} 2}$ interaction is much shorter (by $39.5 \mathrm{pm}$ ) in $\mathbf{5 c}$ than in $\mathbf{4 c}$, but longer by $2.2 \mathrm{pm}$ compared to $\mathbf{4 b}$. The increase in the number of water molecules up to five further decreases the activation enthalpy for the hydrolysis reaction (only the reaction across the $\mathrm{N}=\mathrm{S}$ bond was studied), but the barrier through $\mathbf{5 c - T S b}$ is only $1.6 \mathrm{kcal} \mathrm{mol}^{-1}$ smaller than that in the corresponding reaction with three water molecules (4c-TSb).

Our results from the study of the influence of the number of water molecules in the hydrolysis of $N$-sulfinylaniline (1) are summarized in Fig. 7, which shows the decrease in the activation enthalpy with an increase in the number of water molecules for both pathways (reaction across the $\mathrm{S}=\mathrm{O}$ and the $\mathrm{N}=\mathrm{S}$ bond). For the reaction across $\mathrm{N}=\mathrm{S}$ with one water molecule, the grey zone in Fig. 7, see the previous discussion. ${ }^{7}$ The reaction barriers with one water molecule are prohibitively large, and therefore two water molecules are important for hydrolysis, as is suggested by the solvent isotope effect (12). Similar conclusions were drawn in the computational study of HNCO hydrolysis (16). However, there is a crossover in mechanism at this point, and participation of a third water molecule only benefits the reaction across the $\mathrm{N}=\mathrm{S}$ bond, in contrast to HNCO hydrolysis (16). Such a
Fig. 7. Dependence of the activation barrier of the hydrolysis reaction on the number of water molecules. See text for the grey zone.

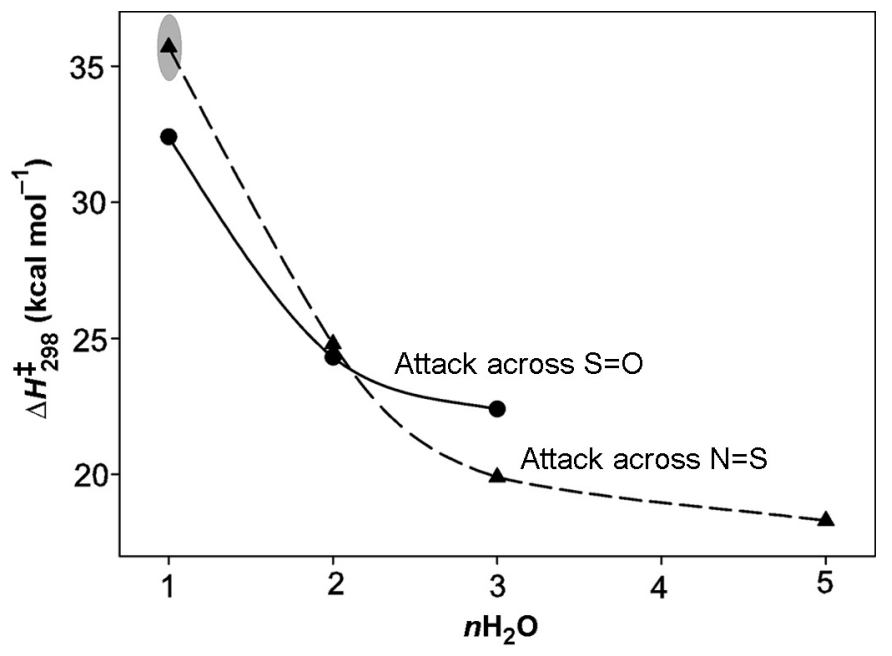

third-order dependence on water concentration has been proposed for the hydrolysis of the related 4-chlorophenyl isocyanate (15). Figure 7 also suggests that the values for the enthalpy barriers are more or less converged for both pathways (with three water molecules for attack across $\mathrm{S}=\mathrm{O}$ and five water molecules for that across $\mathrm{N}=\mathrm{S}$ ), and that larger numbers of water molecules need not be considered. The "converged" values for the activation enthalpy of about $23 \mathrm{kcal} \mathrm{mol}^{-1}$ for path a and $18 \mathrm{kcal} \mathrm{mol}^{-1}$ for path $\mathrm{b}$ are obviously still much higher than the experimentally determined values of 9.88 (11) and $5.7 \mathrm{kcal} \mathrm{mol}^{-1}$ (12). But as both experimental barriers were determined for a catalyzed hydrolysis (autocatalysis from aniline in the former case, pyridine catalysis in the latter), this is not surprising. 


\section{Conclusions}

We have presented a computational study on complexes of $N$-sulfinylaniline $(\mathrm{Ph}-\mathrm{N}=\mathrm{S}=\mathrm{O}, \mathbf{1})$ with one to three and five water molecules and on the mechanism of neutral hydrolysis of $\mathbf{1}$. While the complex of $\mathbf{1}$ with one water molecule does not possess an interaction between the sulfur atom and the water oxygen atom, water chains of two, three, and five molecules lead to increasingly strong $\mathrm{S} \cdots \mathrm{O}$ interactions. In these complexes, water attacks on sulfur close to perpendicular to the NSO plane.

Two mechanisms have been investigated for reaction of $\mathbf{1}$ with one to three water molecules, hydration of the sulfur atom with protonation of either oxygen or nitrogen atoms of the NSO group. The full reaction coordinate was probed for hydrolysis with two water molecules, and S...O interaction with proton transfer from water is found to be the ratedetermining step in both mechanisms. Unrealistically high activation barriers are found for reaction with one water molecule, and two water molecules are important for hydrolysis. This is in good agreement with the first-order dependence in both water and base that was observed for the basecatalyzed reaction, if one water molecule is considered to take the role of the base. Reaction across the $\mathrm{S}=\mathrm{O}$ bond is preferred with one water molecule, whereas an increase in the number of water molecules leads to a change in mechanism. For two water molecules, both mechanisms are equally probable; for three water molecules, reaction across the $\mathrm{N}=\mathrm{S}$ bond is favoured. As expected, the calculated enthalpies of activation for the neutral hydrolysis reaction are several kcal $\mathrm{mol}^{-1}$ larger than the experimentally determined barriers for the base-catalyzed reaction.

The results presented here have revealed differences between PhNSO and HNCO, the smallest member of the related isocyanates, in both complexation with water and mechanism for hydrolysis with an increasing number of water molecules. We are currently investigating this further with a study of substituent effects in $N$-sulfinylamine hydrolysis.

\section{Acknowledgments}

Calculations were performed at the Centre for Research in Molecular Modeling (CERMM), which was established with the financial support of the Concordia University Faculty of Arts and Science, the Ministère de l'Éducation du Québec (MEQ), and the Canada Foundation for Innovation (CFI). This work was supported by a research grant from the Natural Sciences and Engineering Research Council of Canada (NSERC).

\section{References}

1. H.M. Muchall. J. Phys. Chem. A, 105, 632 (2001).

2. H.M. Muchall. ARKIVOC, 82 (2001).

3. A. Michaelis. Chem. Ber. 22, 2228 (1889).

4. A. Michaelis and G. Junghans. Ann. Chem. 274, 233 (1893).

5. P. Hanson and W.A. Stockburn. J. Chem. Soc. Perkin Trans. 2, 589 (1985).

6. P. Hanson and S.A.C. Wren. J. Chem. Soc. Perkin Trans. 2, 197 (1987).
7. P. Hanson and S.A.C. Wren. J. Chem. Soc. Perkin Trans. 1, 2089 (1990).

8. P. Rajagopalan and H.U. Daeniker. Angew. Chem. Int. Ed. Engl. 2, 46 (1963).

9. G.R. Collins. J. Org. Chem. 29, 1688 (1964).

10. A. Michaelis. Ber. 24, 745 (1891).

11. T.L. Dawson. Ph.D. thesis, University of Kentucky, Lexington, Kentucky. 1960.

12. D.F. Mironova and O.Y. Konoplya. Ukr. Khim. Zh. (Russ. Ed.), 42, 374 (1976).

13. A.F. Hegarty, C.N. Hegarty, and F.L. Scott. J. Chem. Soc. Perkin Trans. 2, 1166 (1975).

14. E.A. Castro, R.B. Moodie, and P.J. Sansom. J. Chem. Soc. Perkin Trans. 2, 739 (1985).

15. R.S. Satchell and R. Nyman. J. Chem. Soc. Perkin Trans. 2, 901 (1981).

16. G. Raspoet, M.T. Nguyen, M. McGarraghy, and A.F. Hegarty. J. Org. Chem. 63, 6867 (1998).

17. R.M. Romano, C.O. Della Védova, and R. Boese. J. Mol. Struct. 475, 1 (1999).

18. A.D. Becke. J. Chem. Phys. 98, 5648 (1993).

19. C. Lee, W. Yang, and R.G. Parr. Phys. Rev. B, 37, 785 (1988).

20. M.J. Frisch, G.W. Trucks, H.B. Schlegel, G.E. Scuseria, M.A. Robb, J.R. Cheeseman, V.G. Zakrzewski, J.A. Montgomery, Jr., R.E. Stratmann, J.C. Burant, S. Dapprich, J.M. Millam, A.D. Daniels, K.N. Kudin, M.C. Strain, O. Farkas, J. Tomasi, V. Barone, M. Cossi, R. Cammi, B. Mennucci, C. Pomelli, C. Adamo, S. Clifford, J. Ochterski, G.A. Petersson, P.Y. Ayala, Q. Cui, K. Morokuma, P. Salvador, J.J. Dannenberg, D.K. Malick, A.D. Rabuck, K. Raghavachari, J.B. Foresman, J. Cioslowski, J.V. Ortiz, A.G. Baboul, B.B. Stefanov, G. Liu, A. Liashenko, P. Piskorz, I. Komaromi, R. Gomperts, R.L. Martin, D.J. Fox, T. Keith, M.A. Al-Laham, C.Y. Peng, A. Nanayakkara, M. Challacombe, P.M.W. Gill, B. Johnson, W. Chen, M.W. Wong, J.L. Andres, C. Gonzalez, M. Head-Gordon, E.S. Replogle, and J.A. Pople. GAUSSIAN 98. Revision A.11 [computer program]. Gaussian, Inc., Pittsburgh, Penn. 2001.

21. S.F. Boys and F. Bernardi. Mol. Phys. 19, 553 (1970).

22. S. Antonczak, M.F. Ruiz-López, and J.L. Rivail. J. Am. Chem. Soc. 116, 3912 (1994).

23. C. Gonzalez and H.B. Schlegel. J. Chem. Phys. 90, 2154 (1989).

24. C. Gonzalez and H.B. Schlegel. J. Phys. Chem. 94, 5523 (1990).

25. R.F.W. Bader. Atoms in molecules: A quantum theory. Oxford University Press, Oxford. 1990.

26. R.F.W. Bader. AIMPAC module PROAIM [computer program]. Available from http://www.chemistry.mcmaster.ca/aimpac/ 1982.

27. E.D. Glendening, A.E. Reed, J.E. Carpenter, and F. Weinhold. QCPE Bull. 10, 58 (1990).

28. A.E. Reed, L.A. Curtiss, and F. Weinhold. Chem. Rev. 88, 899 (1988).

29. G. Cerioni, N. Culeddu, and A. Plumitallo. Tetrahedron, 49, 2957 (1993).

30. F. Bernardi, I.G. Csizmadia, and A. Mangini. Organic sulfur chemistry. Theoretical and experimental advances. Vol. 19. Elsevier, Amsterdam, Oxford, New York, Tokyo. 1985. p. 195.

31. L.A. Curtiss, D.J. Frurip, and M. Blander. J. Chem. Phys. 71, 2703 (1979).

32. Z. Wu, F. Ban, and R.J. Boyd. J. Am. Chem. Soc. 125, 6994 (2003).

33. W. Liang, H. Li, X. Hu, and S. Han. J. Phys. Chem. A, 108, 10219 (2004). 